\title{
How Might Team Approaches to Care Affect Panel Size?
}

Ann Fam Med 2012;10:iii. doi:10.1370/afm.1436

$\mathrm{T}$ The Annals of Family Medicine encourages readers to develop a learning community of those seeking to improve health care and health through enhanced primary care. You can participate by conducting a RADICAL journal club and sharing the results of your discussions in the Annals online discussion for the featured articles. RADICAL is an acronym for Read, Ask, Discuss, Inquire, Collaborate, Act, and Learn. The word radical also indicates the need to engage diverse participants in thinking critically about important issues affecting primary care and then acting on those discussions. ${ }^{1}$

\section{HOW IT WORKS}

In each issue, the Annals selects an article or articles and provides discussion tips and questions. We encourage you to take a RADICAL approach to these materials and to post a summary of your conversation in our online discussion. (Open the article online and click on "TRACK Comments: Submit a response.") You can find discussion questions and more information online קim at: http://www.AnnFamMed.org/AJC/.

\section{CURRENT SELECTION}

\section{Article for Discussion}

Altschuler J, Margolius D, Bodenheimer T, Grumbach KT. Estimating a reasonable patient panel size for primary care physicians with teambased task delegation. Ann Fam Med. 2012;10(5):396-400.

\section{Discussion Tips}

Team approaches to care are a centerpiece of the patient-centered medical home. ${ }^{2}$ But how to develop teams is a challenge, ${ }^{3}$ as are who should be on the team and how sharing work among team members could affect panel size. ${ }^{4,5}$ This article addresses how team approaches to care might affect the patient panel size for primary care physicians.

\section{Discussion Questions}

- What questions are asked by this study?

- How does this study advance beyond previous research and clinical practice on this topic? How are the study questions relevant for current efforts to reenergize family medicine and reform primary care?

- How strong is the study design for answering the question?

- What are the key assumptions and data sources?

How do they affect your confidence in the findings?

- To what degree can the findings be accounted for by:

1. How patients were selected, excluded, or lost to follow-up?

2. How the main variables were measured?

3. Confounding (false attribution of causality because 2 variables discovered to be associated actually are associated with a 3rd factor)?

4. Chance?

5. How the findings were interpreted?

- What are the main study findings?

- How comparable are the scenarios to your practice?

- How transportable are the findings?

- What contextual factors are important for interpreting the findings?

- How might this study change your practice? Policy? Education? Research?

- Who are the constituencies are for the findings, and how might they be engaged in interpreting or using the findings?

- What are the next steps in interpreting or applying the findings, and what researchable questions remain?

\section{References}

1. Stange KC, Miller WL, McLellan LA, et al. Annals Journal Club: It's time to get RADICAL. Ann Fam Med. 2006;4(3):196-197.

2. Patient-Centered Primary Care Collaborative. The Patient-Centered Primary Care Collaborative. http://www.pcpcc.net/index.php. Accessed Aug 2, 2012.

3. Miller WL, Crabtree BF, Nutting PA, Stange $K C$, Jaén CR. Primary care practice development: a relationship-centered approach. Ann Fam Med. 2010;8(Suppl 1):S68-S79, S92.

4. Reid RJ, Coleman K, Johnson EA, et al. The group health medical home at year two: cost savings, higher patient satisfaction, and less burnout for providers. Health Aff (Millwood). 2010;29(5):835-843.

5. Kuzel AJ, Engel JD. Restoring Primary Care; Reframing Relationships and Redesigning Practice. Oxford: Radcliffe Publishing; 2011. 